\title{
ANALISA EKONOMI PROYEK PADA PEMBANGUNAN PALANGKA RAYA MALL
}

\author{
Rida Respati \\ Program Studi Teknik Sipil UM Palangka Raya
}

\begin{abstract}
ABSTRAK
Bangunan memegang peranan penting dalam kehidupan masyarakat dan sering kali mempengaruhi suasana hidup bagi setiap individu. Sebagian besar dari kehidupan manusia berada di sekitar atau di dalam bangunan, seperti perumahan, kantor-kantor, tempat-tempat pendidikan, pabrik-pabrik, rumah sakit, jembatan dan sebagainya. Pengaruh yang sedemikian luas itu mengakibatkan sektor bangunan memegang peranan penting dalam meningkatkan kesejahteraan dan perekonomian negara.

Tujuan dari penelitian ini adalah untuk menganalisa besarnya investasi yang dikeluarkan untuk pembangunan Gedung Palangka Raya Mall, apakah akan memberikan keuntungan bagi investor dan pemerintah daerah.

Pengumpulan data diperoleh dari wawancara (interview) yang kompeten dan pengamatan (observation), juga dari buku-buku, jurnal, dan literatur yang relevan.

Hasil Dari hasil perhitungan yang ada, biaya pembangunan dalam waktu hampir 7 tahun tahun akan BEP (break even point), dan ini sangat menguntungkan bagi investor sehingga dengan sisa umur bangunan adalah keuntungan bagi investor dan karena tanah yang digunakan adalah tanah milik pemerintah daerah provinsi, maka setelah habis masa pinjam 40 tahun akan dikembalikan kepada pemerintah provinsi beserta bangunannya, hal ini pun menjadi keuntungan bagi pemerintah daerah.

Untuk itu disarankan, bangunan yang ada sudah cukup memadai, sebaiknya perlu didukung dengan fasilitas dan pelayanan yang baik. Sebaiknya parkir diatur sedemikian rupa sehingga pengunjung merasa nyaman dan tidak was-was saat meninggalkan kendaraan di tempat parkir.
\end{abstract}

\section{Kata kunci : Ekonomi, Proyek, Gedung, Palangka Raya}




\section{PENDAHULUAN}

\section{Latar Belakang}

Bangunan memegang peranan penting dalam kehidupan masyarakat dan sering kali mempengaruhi suasana hidup bagi setiap individu. Sebagian besar dari kehidupan manusia berada di sekitar atau di dalam bangunan, seperti perumahan, kantor-kantor, tempat-tempat pendidikan, pabrikpabrik, rumah sakit, jembatan dan sebagainya. Pengaruh yang sedemikian luas itu mengakibatkan sektor bangunan memegang peranan penting dalam meningkatkan kesejahteraan dan perekonomian negara.

Kalimantan Tengah merupakan Provinsi terbesar ketiga di wilayah Indonesia, dengan wilayah seluas $153.000 \mathrm{~km} 2$ atau 1,5 kali Pulau Jawa dan $750 \mathrm{~km}$ panjang pantai. Kalimantan Tengah berpenduduk sekitar 1.912.747 jiwa yang penyebarannya rata-rata 13 orang per kilometer persegi. Dengan bertambah dan berkembangnya penduduk di Kalimantan Tengah khususnya Palangka Raya, menarik investor untuk menanamkan modal di Kalimantan Tengah, yaitu dengan membangun sebuah pusat perbelanjaan yang pertama di Kalimantan Tengah.

Sejak dibangunnya Palangka Raya Mall sangat mendukung perekonomian dan kesejahteraan masyarakat disekitar pusat perbelanjaan tersebut, pertumbuhan perekonomian masyarakat semakin membaik, meningkatkan produktivitas lahan, membuka lapangan kerja baru sehingga pengangguran berkurang, dan masih banyak lagi dampak positif yang dirasakan. Adapun dampak negatif yang dirasakan adalah menurunnya kualitas budaya, kenyamanan dan keamanan.

\section{Tujuan dilakukan Penelitian}

Menganalisa besarnya investasi yang dikeluarkan untuk pembangunan Gedung Palangka Raya Mall, apakah akan memberikan keuntungan bagi investor dan pemerintah daerah.

\section{Tinjauan Pustaka}

Untuk menentukan proyek dapat dikatakan layak atau tidak maka perlu dilakukan berbagai analisa, yaitu analisa komersial, analisa finansial dan analisa ekonomi, di samping itu perlu diadakan perbandingan antara keuntungan (benefit) dan biaya (cost) selama umur ekonomis proyek.

\section{Metode -Metode Perhitungan}

Suatu investasi merupakan kegiatan menanamkan modal jangka panjang, dimana selain investasi tersebut perlu pula disadari bahwa investasi akan diikuti sejumlah pengeluaran lain yang secara periodic perlu disiapkan. Pengeluaran tersebut terdiri dari biaya operasional (operation cost), biaya perawatan (maintenance cost), dan biaya-biaya lain yang tidak dapat dihindarkan. Terdapat berbagai metode dalam mengevaluasi kelayakan investasi yang umum dipakai, yaitu:

a. Metode Net Present Value (NPV)

b. Metode Annual Equivalent (AE)

c. Metode Internal Rate of Return (IRR)

d. Metode Benefit Cost Ratio (BCR)

e. Metode Payback Period (PBP)

Adapun proses penelitian ini seperti diagram alir penelitian pada Gambar A.1 seperti dibawah ini:

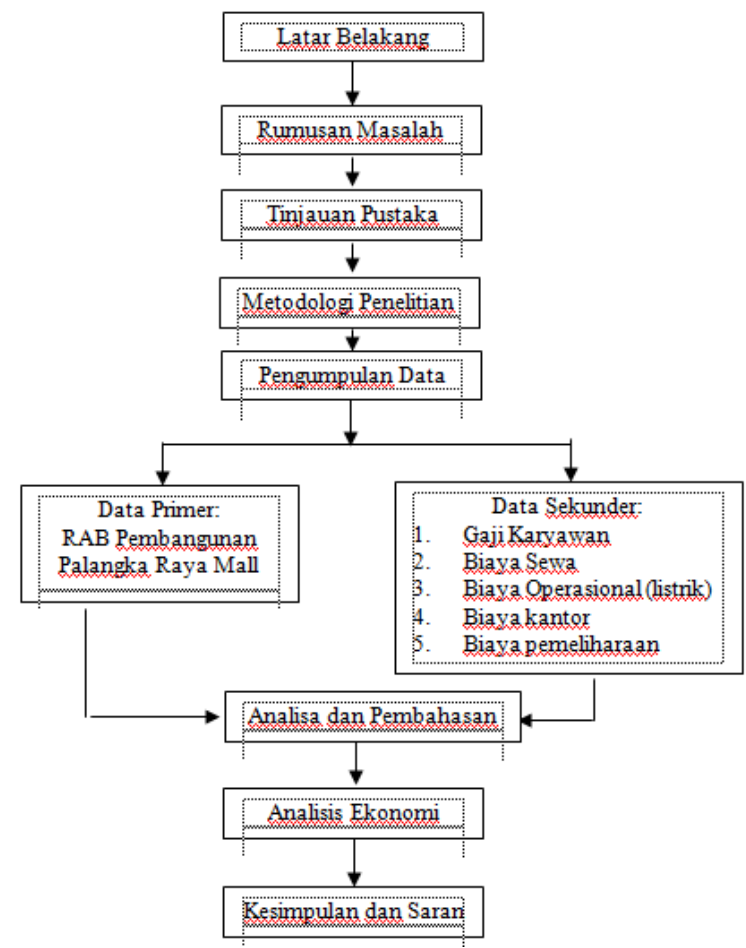

Gambar A.1 Diagram Alir Penelitian

\section{Jenis dan Pendekatan Penelitian}

Jenis penelitian ini adalah penelitian lapangan (field research). Penelitian lapangan adalah penelitian yang menggunakan kehidupan nyata sebagai tempat kajian. Keadaan lapangan berjalan sebagaimana biasa. Penelitian lapangan mempunyai keuntungan karena lebih mendekati 
realitas sehingga hasilnya mencerminkan keadaan yang nyata.

Pendekatan penelitian dilakukan melalui pendekatan kualitatif, artinya data dikumpulkan bukan berupa angka-angka melainkan data tersebut berasal dari pedoman wawancara, pengamatan dan dokumen resmi lainnya. Oleh karena itu pendekatan kualitatif dalam penelitian ini lebih diarahkan pada realita dengan teori dengan menggunakan metode deskriptif. Menurut Keirl dan Miller yang dikutip Lexy J. Moleong bahwa penelitian kualitatif adalah tradisi tertentu dalam ilmu pengetahuan sosial yang secara fundamental bergantung pada pengamatan pada manusia pada kawasannya sendiri dan berhubungan dengan orang-orang tersebut dalam bahasanya dan peristilahannya tersebut dalam bahasanya dan peristilahannya (Lexy J. Moleong, 2004).

\section{DATA DAN SUMBER DATA}

Koleksi data merupakan tahapan dalam proses penelitian yang penting karena hanya dengan mendapatkan data yang tepat maka proses penelitian akan berlangsung sampai mendapatkan jawaban dari perumusan masalah yang sudah ditetapkan. Pada penelitian ini jenis data yang digunakan adalah data primer dan sekunder (Jonathan Sarwono, Metode Penelitian Kuantitatif \& Kualitatif, (Yogyakarta : Graha Ilmu, 2006).

Data primer adalah data yang berasal dari sumber asli atau pertama. Data ini tidak tersedia dalam bentuk terkompilasi atau dalam bentuk filefile. Data-data primer pada penelitian ini diperoleh melalui wawancara dan pengamatan sedangkan data sekunder merupakan data yang sudah tersedia sehingga tinggal mencari dan mengumpulkannya (Jonathan Sarwono, 2006). Data-data sekunder pada penelitian ini didapatkan dari buku-buku literatur dan dokumen resmi yang berhubungan penelitian.

Kemudian, sumber data diperoleh dari lapangan dengan wawancara, pengamatan dan dokumen resmi. Sumber data dalam penelitian ini dilakukan dengan mendapatkan informasi langsung melalui wawancara dengan pelaksana Paket Pembangunan Jalan Lingkar Luar Kota Palangka Raya. Kemudian, sumber data yang lain diperoleh dengan pengamatan langsung dilapangan dengan mencatat kondisi yang sebenarnya dan berusaha mendapatkan dokumen resmi yang terkait dengan penelitian.

\section{Prosedur Pengumpulan Data}

Prosedur pengumpulan data dilakukan sebagai berikut :

\section{Wawancara (Interview)}

Wawancara adalah percakapan dengan maksud tertentu. Percakapan itu dilakukan oleh dua pihak, yaitu pewawancara (interviewer) yang mengajukan pertanyaan dan yang diwawancarai (interviewe) yang memberikan jawaban atas pertanyaan itu. Maksud mengadakan wawancara, seperti ditegaskan oleh Lincoln dan Guba yang dikutip Lexy J. Moleong bahwa untuk mengkonstruksi mengenai orang, kejadian, kegiatan, organisasi, perasaan, motivasi, tuntutan, kepedulian dan lain-lain (Lexy J. Moleong, 2004). Prosedur pengumpulan data dengan wawancara dilakukan dengan mengajukan beberapa pertanyaan dan yang diwawancarai memberikan jawaban atas pertanyaan itu.

\section{Pengamatan (Observation)}

Pengamatan (observation) adalah melakukan pengamatan secara langsung ke objek penelitian untuk melihat dari dekat kegiatan yang dilakukan. Prosedur pengumpulan data dengan pengamatan dilakukan dengan melihat dan mencatat tentang objek penelitian. Adapun pengamatan dibuat dalam pedoman pengamatan dengan topik Analisis Keselamatan dan Kesehatan Kerja Pada Paket Pekerjaan Pembangunan Jalan Lingkar Luar Kota Palangka Raya, dan seterusnya.

\section{Dokumentasi (Document)}

Dokumentasi (document) adalah ditujukan untuk memperoleh data langsung dari tempat penelitian, meliputi buku-buku yang relevan, peraturan-peraturan, laporan kegiatan, foto-foto, film dokumenter dan data yang relevan penelitian. Prosedur pengumpulan data dengan dokumentasi akan diverifikasi yang sesuai dengan objek penelitian.

\section{ANALISIS DATA}

Analisis data merupakan bagian yang amat penting dalam metode penelitian karena dengan analisis data tersebut dapat diberi arti dan makna yang berguna dalam memecahkan masalah penelitian (Moh. Nazir, 2003). Proses analisis data dimulai dengan menelaah seluruh data yang tersedia dari berbagai sumber, yaitu dari wawancara, pengamatan yang sudah dituliskan dalam catatan lapangan, dokumen pribadi, dokumen resmi, gambar, foto dan sebagainya. Setelah dibaca dipelajari, ditelaah, maka 
selanjutnya ialah mereduksi data yang dilakukan dengan jalan membuat abstraksi. Abstraksi merupakan usaha membuat rangkuman yang inti, proses, dan pernyataan-pernyataan yang perlu dijaga sehingga tetap berada di dalamnya.

Langkah selanjutnya adalah menyusunnya dalam satuan-satuan. Satuan-satuan kemudian dikategorisasikan pada langkah berikutnya. Kategori-kategori itu dilakukan sambil membuat coding. Manfaat coding adalah untuk merinci, menyusun konsep (conceptualized) dan membahas kembali semuanya itu dengan cara baru. Ini merupakan cara yang terkendali dimana teori dibangun dari data. Tahap akhir dari analisis data ini ialah mengadakan pemeriksaan keabsahan data. Setelah selesai tahap ini, mulailah kini tahap penafsiran data dalam mengolah hasil sementara menjadi teori substantif dengan menggunakan beberapa metode tertentu (Lexy J. Moleong, 2004).

\section{Interpretasi Data}

Interpretasi data atau penafsiran data tidak lain dari pencarian pengertian yang lebih luas tentang penemuan-penemuan. Interpretasi data tidak dapat dipisahkan dari analisis, sehingga sebenarnya penafsiran merupakan aspek tertentu dari analisis, dan bukan merupakan bagian yang terpisah dari analisis. Secara umum, penafsiran atau interpretasi data adalah penjelasan yang terperinci tentang arti yang sebenarnya dari materi yang dipaparkan (Moh. Nazir, 2003). Dari uraian tersebut, bahwa tujuan utama penafsiran data atau interpretasi data tidak lain ialah mencapai teori substantive (Lexy J. Moleong, 2004).

\section{HASIL PEMBAHASAN}

\section{Data Primer}

Data primer adalah data yang diperoleh langsung, nilai riil dari biaya yang ditanamkan dalam rangka menyiapkan kebutuhan usaha untuk siap beroperasi dengan baik. Dalam hal ini Modal Pembangunan Palangka Raya Mall adalah sebesar Rp. 29.045.291.300,-.

Data-data sekunder adalah : Data-data yang diperoleh dari wawancara langsung dilapangan, misalnya:

1. Biaya yang dikeluarkan untuk membayar gaji pegawai dan sekuriti

2. Biaya operasional dan biaya perawatan gedung. Biaya Operasional adalah biaya yang dikeluarkan dalam rangka menjalankan aktivitas usaha tersebut sesuai dengan tujuannya. Contohnya: pembayaran listrik. Biaya Perawatan adalah biaya yang diperuntukan dalam rangka menjaga/menjamin performance kerja fasilitas atau peralatan agar selalu prima dan siap dipergunakan. Contohnya:

a. Biaya perawatan Rutin

b. Biaya perwatan periodik

\section{Data Sekunder}

\begin{tabular}{|c|c|}
\hline URAIAN & Biaya per bulan \\
\hline $\begin{array}{l}\text { Biaya gaji pegawai } \\
\text { - Sekuriti } 3 \text { regu } 8 \text { org @ } \\
\text { Rp. } 725.000,-\end{array}$ & $\begin{array}{l}=3 \times 8 \times \mathrm{Rp} . \\
725.000,- \\
=\text { Rp. } 17.400 .000,-\end{array}$ \\
\hline $\begin{array}{l}\text { Gaji pegawai } \\
-4 \text { org Administrasi @ Rp. } \\
1.500 .000,-\end{array}$ & $\begin{array}{l}=4 \times \mathrm{Rp} \\
1.500 .000 \\
=\text { Rp. } 6.000 .000,-\end{array}$ \\
\hline $\begin{array}{l}\text { Gaji pegawai } \\
-1 \text { org Keuangan Rp. } \\
1.800 .000,- \\
-1 \text { org manager Food Cout } \\
\text { Rp. } 2.000 .000,- \\
-1 \text { org manager Building }\end{array}$ & $\begin{array}{l}=\text { Rp. } 1.800 .000,- \\
=\text { Rp. } 2.000 .000,- \\
=\text { Rp. } 6.000 .000,-\end{array}$ \\
\hline $\begin{array}{l}\text { Biaya pemeliharaan dan } \\
\text { administrasi }\end{array}$ & $=$ Rp.5.000.000,- \\
\hline Biaya Listrik & $\begin{array}{l}=\mathrm{Rp} \\
200.000 .000,-\end{array}$ \\
\hline JUMLAH & Rp 238.200.000,- \\
\hline
\end{tabular}

\begin{tabular}{|c|c|}
\hline URAIAN & Biaya per Tahun \\
\hline $\begin{array}{l}\text { Biaya gaji pegawai } \\
\text { - Sekuriti } 3 \text { regu } 8 \text { org @ } \\
\text { Rp. } 725.000,-\end{array}$ & $\begin{array}{l}=\text { Rp. } 17.400 .000,-\mathrm{x} \\
12 \\
=\text { Rp. } 208.800 .000,-\end{array}$ \\
\hline $\begin{array}{l}\text { Gaji pegawai } \\
\text { - } 4 \text { org Administrasi @ } \\
\text { Rp. 1.500.000,- }\end{array}$ & $\begin{array}{l}=\text { Rp. } 6 \cdot 000.000 \mathrm{x} \\
12 \\
=\text { Rp. } 72 \cdot 000 \cdot 000,-\end{array}$ \\
\hline $\begin{array}{l}\text { Gaji pegawai } \\
-1 \text { org Keuangan Rp. } \\
1.800 .000,- \\
-1 \text { org manager Food } \\
\text { Cout Rp. } 2.000 .000,- \\
-1 \text { org manager Building }\end{array}$ & $\begin{array}{l}=\text { Rp. } 21 \cdot 600 \cdot 000,- \\
=\text { Rp. } 24 \cdot 000 \cdot 000,- \\
=\text { Rp. } 72 \cdot 000 \cdot 000,-\end{array}$ \\
\hline $\begin{array}{l}\text { Biaya pemeliharaan dan } \\
\text { administrasi }\end{array}$ & $=$ Rp. 60.000.000,- \\
\hline Biaya Listrik & $\begin{array}{l}=\mathrm{Rp} . \\
2.400 .000 .000,-\end{array}$ \\
\hline JUMLAH & $\begin{array}{l}\text { Rp. } \\
\text { 2.858.400.000,- }\end{array}$ \\
\hline
\end{tabular}


Biaya pemasukan dari pembangunan mall tersebut adalah:

1. Biaya sewa per counter penjualan dalam $\mathrm{m} 2$ adalah $\mathrm{Rp} 150.000,-/ \mathrm{b} \ln / \mathrm{m} 2$

2. Luas Counter yang sudah terisi $\pm 4.000 \mathrm{~m} 2$.

Sehingga pendapatan per tahun adalah $4.000 \mathrm{~m} 2$ x Rp. 150.000,- x 12 = Rp. 7.200.000.000,-/thn.

Suatu investasi merupakan kegiatan menanamkan modal jangka panjang, dimana selain investasi tersebut perlu pula disadari dari awal bahwa investasi akan diikuti oeh sejumlah pengeluaran lain yang secara periodik perlu disiapkan. Pengeluaran tersebut terdiri dari biaya operasional (operation cost), biaya perawatan (maintenance cost) dan biaya-biaya lain yang tidak dapat dihindarkan.

1. Metode Net Present Value (NPV)

Net Present Value (NPV) adalah menghitung nilai bersih (netto) pada waktu sekarang (present).

Diketahui:

$\begin{array}{lll}\text { - Investasi (I) } & : & R p \cdot 29.045 .291 .300,- \\ \text { - Annual Benedit (Ab) } & : & R p \cdot 7.200 .000 .000,- \\ \text { - Annual Cost (Ac) } & : & R p .2 .858 .400 .000,- \\ \text { - Umur Investasi } & : & 40 \text { tahun } \\ \text { - Suku bunga } & : 12 \%\end{array}$

\section{$\mathbf{N V P}=$}

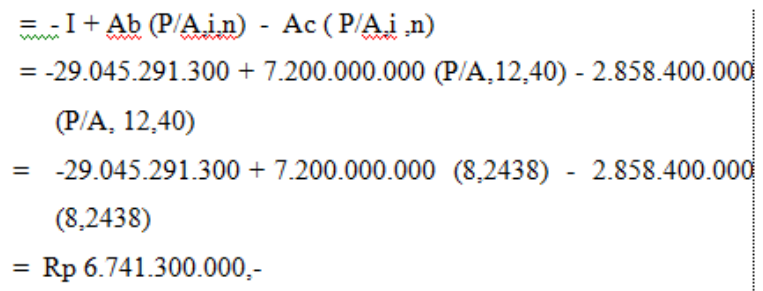

Karena NVP 》> 0, maka rencana investasi direkomendasikan layak secara ekonomis.

2. Metode Internal Rate of Return (IRR) Investasi layak apabila IRR $\geq$ MARR IRR akan diperoleh saat NPV $=0$, perlu di cari nilai NPV dengan i yang berbeda untuk mendapatkan NPV mendekati nol

Jika i $=8 \%$

$\mathrm{NPV}=-\mathrm{I}+\mathrm{Ab}(\mathrm{P} / \mathrm{A}, \mathrm{i}, \mathrm{n})-\mathrm{Ac}(\mathrm{P} / \mathrm{A}, \mathrm{i}, \mathrm{n})$ $=-29.045 .291 .300+7.200 .000 .000$

$$
\begin{aligned}
&(\mathrm{P} / \mathrm{A}, 8,40)-2.858 .400 .000 \\
&(\mathrm{P} / \mathrm{A}, 8,40) \\
&=-29.045 .291 .300+7.200 .000 .000 \\
&(11,9246)-2.858 .400 .000 \\
&(11,9246) \\
&= \mathrm{Rp} \mathrm{22.721.800.000,-} \\
& \mathrm{Jika} \mathrm{i}=15 \% \\
& \mathrm{NPV}=-\mathrm{I}+\mathrm{Ab}(\mathrm{P} / \mathrm{A}, \mathrm{i}, \mathrm{n})-\mathrm{Ac}(\mathrm{P} / \mathrm{A}, \mathrm{i}, \mathrm{n}) \\
&=-29.045 .291 .300+7.200 .000 .000 \\
& \\
&(\mathrm{P} / \mathrm{A}, 15,40)-2.858 .400 .000 \\
&(\mathrm{P} / \mathrm{A}, 15,40) \\
&=-29.045 .291 .300+7.200 .000 .000 \\
&(6,6418)-2.858 .400 .000(6,6418) \\
&=-\mathrm{Rp} 214.000 .000,-
\end{aligned}
$$

Ternyata IRR $=0$ berada diantara $\mathrm{i}=8 \%$ dengan $\mathrm{i}=15 \%$, selanjutnya dengan metode interpolasi akan diperoleh IRR, yaitu:

Karena IRR $=14,93 \%$ >> MARR $=12 \%$, maka rencana investasi tersebut direkomendasikan layak secara ekonomis dilaksanakan.

3. Metode Benefit Cost Ratio (BCR)

Metode Benefit Cost Ratio (BCR) adalah salah satu metode yang sering digunakan dalam tahap-tahap evaluasi awal perencanaan investasi atau sebagai analisis tambahan dalam rangka menvalidasi hasil evaluasi yang telah dilakukan dengan metode lainnya.

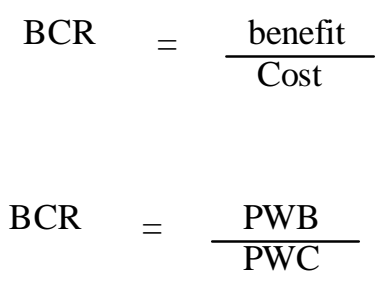

$\begin{aligned} \text { Dimana: PWB } & =\text { Present Worth of benefit } \\ \text { PWC } & =\text { Present Worth of Cost }\end{aligned}$

$$
\begin{aligned}
\mathrm{PWB} & =\mathrm{Ab}(\mathrm{P} / \mathrm{A}, \mathrm{i}, \mathrm{n}) \\
& =7.200 .000 .000(\mathrm{P} / \mathrm{A}, 12,40) \\
& =7.200 .000 .000(8,2438) \\
& =59.355 .360 .000
\end{aligned}
$$

$$
\begin{aligned}
\mathrm{PWC} & =\mathrm{I}+\mathrm{Ac}(\mathrm{P} / \mathrm{A}, \mathrm{i}, \mathrm{n}) \\
= & 29.045 .291 .300+2.858 .400 .000 \\
& (\mathrm{P} / \mathrm{A}, 12,30) \\
= & 29.045 .291 .300+2.858 .400 .000 \\
& (8,2438)
\end{aligned}
$$


$=52.614 .077 .000$

$\mathrm{BCR}=1,1281$

Karena nilai $\mathrm{BCR}=1,1281 \gg 1$, maka investasi ini layak ekonomis (feasible) dan rencana investasi rekomendasikan untuk diterapkan

4. $\quad$ Metode Payback Period (PBP)

Metode Payback Period (PBP) pada dasarnya bertujuan untuk mengetahui seberapa lama (periode) investasi akan dapat dikembalikan saat terjadinya kondisi pulang pokok (break even point). Lamanya periode pengembalian (k) saat kondisi BEP adalah:

$\begin{aligned} & \mathrm{K}_{(\mathrm{PBP})}=\frac{\text { Investasi }}{\text { Annual Benefit }} \begin{array}{c}\mathrm{X} \text { Periode } \\ \text { waktu }\end{array} \\ & \mathrm{K}_{(\mathrm{PBP})} \\ &=\frac{29.045 .291 .300}{7.200 .000 .000-} \begin{array}{l}\mathrm{X} \\ \text { Period } \\ \end{array} \\ & \begin{array}{l}\mathrm{e} \\ \text { waktu }\end{array}\end{aligned}$

$\mathrm{K}_{(\mathrm{PBP})} \quad=\quad 6,69 \quad$ tahun

Karena $\mathrm{K}=6,69$ tahun $<\mathrm{n}=40$ tahun, maka periode pengembalian investasi memenuhi syarat/layak.

\section{Evaluasi Proyek}

Proyek pembangunan Gedung Palangka Raya Mall merupakan proyek ekonomi mikro yaitu dimana proyek bersifat komersial yang tujuan utamanya untuk memperoleh keuntungan yang sebesar-besarnya walaupun ada tujuan lainnya.

Proyek tersebut telah dibangun dan telah dilakukan evaluasi perhitungan secara ekonomi dan financial, dari segi financial mengunakan metode Metode Net Present Value (NPV) dan metode Metode Internal Rate of Return (IRR), dari analisa tersebut NPV $>0$ dan IRR $>$ MARR. Sehingga secara financial proyek tersebut layak dilaksanakan.

Secara Ekonomi mengunakan metode Benefit Cost Ratio (BCR) dan metode Payback
Period (PBP), dari analisa tersebut $\mathrm{BCR}>1$ dan PBP di dapat nilai $\mathrm{k}=6,69$ tahun $<\mathrm{n}=40$ thn, sehingga secara ekonomi proyek tersebut layak dan sangat menguntungkan.

\section{KESIMPULAN}

Pembangunan Gedung Palangka Raya Mall merupakan investasi yang tepat bagi investor, karena dengan bertambahnya penduduk yang ada di Palangka Raya, dan belum adanya pusat belanja, maka minat penduduk untuk mendatangi mall tersebut sangat besar, selain untuk belanja juga memperoleh hiburan walaupun hanya sekedar berjalan-jalan yang akhirnya akan menambah pemasukan bagi investor.

Dari hasil perhitungan yang ada, biaya pembangunan dalam waktu hampir 7 tahun tahun akan BEP (break even point), dan ini sangat menguntungkan bagi investor sehingga dengan sisa umur bangunan adalah keuntungan bagi investor dan karena tanah yang digunakan adalah tanah milik pemerintah daerah provinsi, maka setelah habis masa pinjam 40 tahun akan dikembalikan kepada pemerintah provinsi beserta bangunannya, hal ini pun menjadi keuntungan bagi pemerintah daerah

Sejak dibangunnya Palangka Raya Mall sangat mendukung perekonomian dan kesejahteraan masyarakat disekitar pusat perbelanjaan tersebut, pertumbuhan perekonomian masyarakat semakin membaik, meningkatkan produktivitas lahan, membuka lapangan kerja baru sehingga pengangguran berkurang, dan masih banyak lagi dampak positif yang dirasakan. Adapun dampak negatif yang dirasakan adalah menurunnya kualitas budaya, serta kenyamanan dan keamanan.

\section{SARAN-SARAN}

1. Bangunan yang ada sudah cukup memadai, sebaiknya perlu didukung dengan fasilitas dan pelayanan yang baik.

2. Sebaiknya parkir diatur sedemikian rupa sehingga pengunjung merasa nyaman dan tidak was-was saat meninggalkan kendaraan di tempat parkir

\section{DAFTAR PUSTAKA}

Degarmo, F.Paul,et.al, 1997, Engineering Economy, 10rd edition, Prentice, Inc, New Jearsey. 
Analisa Ekonomi Proyek Pada Pembangunan..., RIDA RESPATI

Giatman, 2006, Ekonomi Teknik, Rajawali pres, Jakarta.

Kuswadi, 2007, Analisis Keekonomian Proyek, Andi, Yogyakarta.

Pujawan,1995, Ekonomi Teknik, PT Guna Widya, Jakarta

Waldiyono, 2008, Ekonomi teknik, Pustaka Pelajar, Yogyakarta. 